This item was submitted to Loughborough's Research Repository by the author.

Items in Figshare are protected by copyright, with all rights reserved, unless otherwise indicated.

\title{
Mechanisms of fractures in ankle and hind-foot injuries to front seat car occupants - an in-depth accident data analysis
}

PLEASE CITE THE PUBLISHED VERSION

http://dx.doi.org/10.4271/973328

PUBLISHER

(C) SAE

VERSION

AM (Accepted Manuscript)

LICENCE

CC BY-NC-ND 4.0

\section{REPOSITORY RECORD}

Morris, Andrew, Pete Thomas, Andrew M. Taylor, and W. Angus Wallace. 2019. "Mechanisms of Fractures in Ankle and Hind-foot Injuries to Front Seat Car Occupants - an In-depth Accident Data Analysis". figshare. https://hdl.handle.net/2134/14317. 


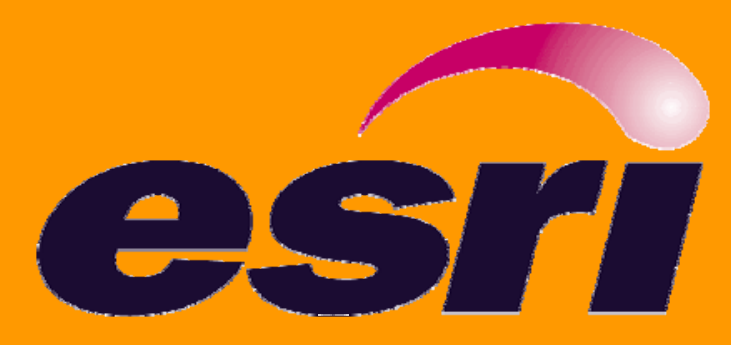

http://www.lboro.ac.uk/esri

This document may be subject to copyright protection.

\section{DO NOT MAKE COPIES OF THIS DOCUMENT}

A public, copyright checked version of this document can be found at the Loughborough University Institutional Repository http://dspace.lboro.ac.uk/dspace/handle/2134/511 
Paper 97S-44

\section{Mechanisms of Fractures in Ankle and Hind- foot Injuries to Front Seat Car Occupants - An In-Depth Accident Data Analysis}

Andrew Morris Pete Thomas

Vehicle Safety Research Centre, Loughborough University, United Kingdom

Andrew M. Taylor W. Angus Wallace University Hospital Nottingham, United Kingdom. 


\section{ABSTRACT}

An in-depth analysis of 200 Abbreviated Injury Score (AIS) 2+ injuries to the lower extremity in frontal collisions has been performed using impairment scales devised by the American Orthopaedic Foot and Ankle Society.

The most important subgroup of injuries were identified as ankle/hindfoot injuries. There were 63 such injuries sustained by 53 occupants and these were analyzed in greater depth.

Inversion or eversion was identified as the mechanism of injury for $40 \%$ of injuries. However in $70 \%$ of these fractures caused by inversion or eversion, minimal or no long term impairment would be expected. Injuries associated with significant long-term impairment were attributed to axial forces (i.e. loads perpendicular to the foot).

Combined vehicle/injury analysis demonstrated a strong association between toe-pan intrusion and these injuries. Interaction between the occupant and the pedals was identified as a probable injury source in only $25 \%$ of injuries to the ankle and hindfoot.

The results of this study are being used to plan a program of biomechanical research to establish injury risk functions for the ankle and hindfoot.

\section{INTRODUCTION}

Lower limb injuries to front seat car occupants are recognized as an important cause of long term disability in survivors of serious crashes (Pattimore et al; 1991). Improvements in car safety have focused on reducing life-threatening injuries to the head, neck and torso. Such measures have had little effect on reducing lower extremity injuries (Dischinger et al.,
1992). As a result of this, injuries to the lower limb will assume greater relative importance in terms of future developments in vehicle safety.

In order to reduce the incidence of lower limb injuries, a better understanding of the mechanisms of injury and tolerances of human tissues to potentially injurious loads is required. Only then will it be possible to develop accurate anthropometric and computer models that will be sensitive enough to detect the risk of injury to the lower limb in test collisions. Without these models, it will be impossible to evaluate modifications in car designs aimed at reducing lower limb injuries.

Despite recent interest in lower extremity injuries, there is still not enough data available from the investigation of real world crashes on the incidence and mechanisms of the injuries that are likely to be a source of long term disability. This study aims to provide this data with particular reference to a sample of United Kingdom (UK) crashes.

The UK data reveals that lower limb injuries account for thirty-seven percent of all injuries sustained by front seat occupants in frontal, side and rear impacts (Pattimore et al; 1991). They are second in frequency only to facial and head injuries. Pattimore et al's study demonstrates that injuries below the knee are the most important in terms of frequency alone (Table 1). A similar distribution of injuries has been found in studies conducted in France (Portier et al, 1993) and the United States (Crandall et al, 1994). 
The use of seat belts has had little effect in reducing injuries to the leg, ankle and foot of car occupants in crashes. The protective effects of belts are largely confined to reducing femoral shaft fractures. (Dischinger et al, 1992; Fildes et al, 1994).

In frontal impacts, the driver is at greater risk of lower extremity injuries than a front seat passenger for two main reasons

1. The driver is more often on the 'struck-side' in the crash.

2. Pedals may influence the type and severity of injury to the driver since even after controlling for seat position, the driver has a 54\% greater risk of sustaining an injury below the knee for the same level of intrusion (Thomas et al, 1995).

Thomas demonstrated that given a constant crash severity, increasing toe-pan intrusion increases the risk of lower leg injury. Other researchers have demonstrated that intrusion is associated with up to $80 \%$ of lower leg fractures (Otte et al, 1992; Fildes et al, 1995). The risk of injury increases sharply beyond $10 \mathrm{cms}$ of residual intrusion with the incidence of an AIS 2+ injury rising to $45 \%$ in the presence of 45 cms of intrusion (Thomas et al, 1995). However, it is not clear exactly how toe-pan intrusion influences injury.

The role of the pedals in injury causation remains controversial. Although some researchers have highlighted an increased risk of driver lower extremity injury associated with pedals (Pattimore et al, 1991; Fildes et al, 1994; Thomas et al, 1995; Morgan et al, 1991 and Otte et al, 1992), the mechanism by which pedals increase the injury risk is not clear. It may be that the pedal is responsible for forcing the driver's foot into extreme dorsiflexion or that by allowing the foot to roll off the pedal, extreme inversion, eversion and external rotation may occur. Another possibility is that the position of the pedal restricts the driver's feet position making contact with intruding structures more likely.

Other sources of injury contact include floor and toe-pan contacts in the absence of intrusion. These are common sites for foot and ankle injuries. However, injuries that occur in this manner do not add a lot to the understanding of injury mechanisms (Fildes et al 1994, Otte et al 1992).
Other studies of lower extremity injuries have looked at the actual mechanism of injury. While the majority of ankle fractures are attributed to indirect loading of the ankle causing inversion or eversion (Lestina et al, 1992), Morgan et al (1991) proposed that dorsiflexion is also an important injury mechanism. The understanding of the mechanisms of injuries to the different parts of the foot is less clear-cut since incidence of injury to separate parts of the foot is relatively low. A variety of mechanisms are proposed including direct blows, crushing and indirectly applied rotation and inversion/eversion forces (Portier et al, 1993; Otte et al, 1992; Lestina et al, 1992)

\section{METHODOLOGY}

The data used in this study are from an ongoing study of vehicle crash performance and occupant injury (the Co-operative Crash Injury Study CCIS) which commenced in the UK in 1983 and is still ongoing. The database holds information on approximately 13,000 vehicles involved in crashes in which there were approximately 20,000 occupants who sustained 85,000 injuries. The current sampling criteria of the CCIS study are;

1. the vehicle involved in the crash was towed away from the scene of the accident to a garage or recovery yard;

2. the vehicle was less than seven years old at the time of the crash (although some older vehicles were included in one section of the sample);

3. there was an injury in the vehicle according to the Department of Transport method of injury classification.

About $80 \%$ of serious and fatal accidents in each study area were investigated along with 10-15\% of slight accidents. The resulting sample includes all levels of injury outcome but is biased towards more serious injuries.

Medical data concerning each occupant was obtained from hospitals and each occupant was also requested to complete a questionnaire which provided additional data several days after the crash. Injuries were coded according to the Abbreviated Injury Scale, 1985 revision. (AAAM, 1985). Latterly, the 1990 revision was used. A more comprehensive overview of the CCIS study can be attained in Mackay et al, 1985. 
Table 1. Numbers of Lower Limb Injury Type and Location for Crash Survivors (From Pattimore et al, 1991)

\begin{tabular}{|l|l|l|l|l|}
\hline & \multicolumn{2}{|l|}{$\begin{array}{l}\text { Survivors of Frontal, Side and Rear } \\
\text { Impacts (N=4837) }\end{array}$} & \multicolumn{2}{l|}{ Survivors of Frontal Impacts (N=2080) } \\
\hline $\begin{array}{l}\text { Lower Limb } \\
\text { Region }\end{array}$ & $\begin{array}{l}\text { Skeletal } \\
\text { (AIS 2+) }\end{array}$ & $\begin{array}{l}\text { Internal Sprain/ } \\
\text { dislocation } \\
\text { (AlS 3+) }\end{array}$ & $\begin{array}{l}\text { Skeletal } \\
\text { (AIS 2) }\end{array}$ & $\begin{array}{l}\text { Internal } \\
\text { AIS 3) }\end{array}$ \\
\hline Pelvis & $98(20 \%)$ & $19(24.7 \%)$ & $22(8.1 \%)$ & $11(25 \%)$ \\
\hline Thigh & $80(16.3 \%)$ & $2(2 \%)$ & $45(16.6 \%)$ & - \\
\hline Knee & $33(6.8 \%)$ & $15(19.5 \%)$ & $19(7.1 \%)$ & $8(18.2 \%)$ \\
\hline Leg & $118(24 \%)$ & $4(5.2 \%)$ & $67(24.8 \%)$ & $1(2.3 \%)$ \\
\hline Foot/Ankle & $161(32.9 \%)$ & $31(48 \%)$ & $117(43.3 \%)$ & $24(54.5 \%)$ \\
\hline
\end{tabular}

A subset of cases from the CCIS database were selected for the current study using the following criteria:

1. all vehicles sustained crashes in the Midlands of England during the period 1983 - 1996;

2. from these, all vehicles which sustained a frontal impact in which the principle direction of force (pdof) was between 1 o'clock and 11 o'clock (i.e. within 45 degrees of 'head-on') were selected. Any vehicles which sustained a subsequent rollover were excluded;

3. of vehicles, only front seat occupants who sustained an Abbreviated Injury Score of 2 or above to the lower extremity were selected;

4. of these occupants, it was only possible to undertake an in-depth examination of the lower extremity injuries of those occupants whose $x$ rays were still available.

5. occupants who had sustained ligament disruptions without fractures or dislocations were not included in this retrospective study. Although ankle sprains are common, they are usually easy to treat and are unlikely to be a source of long term impairment. In addition, it is not possible to diagnose ankle sprains accurately on the basis of $\mathrm{x}$-rays and standard medical records.

The injuries were classified according to the most likely mechanism of injury (e.g. direct blow, bending or twisting). The objective was to define the mechanism of injury by the principal load applied to the injured segment in relation to the standard anatomical position of the body. This classification is based on $\mathrm{x}$-rays of the lower limbs with additional information being obtained from the patient's medical records. The understanding of fracture mechanisms of the lower extremity is based on cadaver lower limbs as well as clinical observations (Taylor et al, 1997).
Each injury was given a severity score and an impairment score according to the Injury Scale (FASS-I) developed by the American Orthopaedic Foot and Ankle Society (Manoli, Prasad and Levine, 1997). The details of this scale are included in Appendix A. The primary function of these scales are as tools for car crash researchers to determine which injuries are a priority for prevention.

The information obtained from medical records was combined with information from the report of the crash investigator and information from the photographs of the car interior. This information was analysed by Orthopaedic specialists, vehicle safety experts and crash investigators. From an analysis of this information, a consensus was reached as to the likely mechanism of injury from contact with the vehicle interior. The details of this classification are included in Appendix B.

\section{Results}

Out of a sample of 200 AIS 2+ lower extremity injuries, injuries to the ankle and hind-foot were identified as the most important in terms of frequency and the long term impairment that they caused.

63 ankle and hind-foot injuries to 53 front seat occupants (46 drivers and 7 passengers) were analysed. An analysis of the data demonstrated that the vehicle, occupant and injury characteristics are representative of a wider sub-set of data that have been gathered for the UK Co-operative Crash Injury Study (CCIS) which itself is considered to be representative of the UK seriously injured car-crash population (Taylor et al, 1997).

The principle direction of force for the occupants was 12 o'clock in $68 \%, 11$ o'clock in $20 \%$ and 1 o'clock in $12 \%$ of impacts. The distribution of crash severity, expressed in terms of $\Delta \mathrm{V}$ is shown in Figure 1 and the distribution of intrusion bands was as follows : 


\section{Intrusion Band}

None

$1-9 \mathrm{~cm}$ of cases within band

$10-24 \mathrm{~cm}$ 15.9

$25-49 \mathrm{~cm}$

23.8

23.8

30.2

$50+\mathrm{cm}$

1.5

Unknown

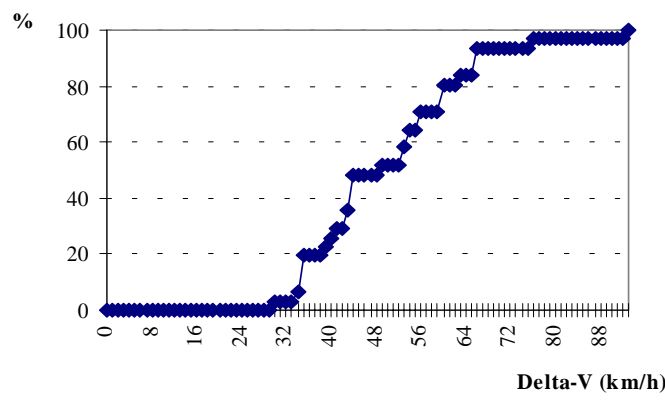

Figure 1. Delta-V distribution of crash severity for ankle and hindfoot injuries

The frequencies of the injury types sustained by the occupants are shown in Table 2 . Injuries to the ankle were the most frequent injuries to this region. A distinction was made between ankle malleolus fractures and ankle pilon fractures because the mechanisms and outcomes of these subsets of ankle injuries are completely different.

The frequency of different mechanisms of injury deduced from analysis of the x-rays of the afflicted limb is detailed in Table 3 . All of the ankle malleolus fractures were caused by rotations of the foot about the ankle joint (abduction, adduction or external rotation). However, the majority of injuries to the Ankle Pilon, the talus and calcaneus were caused by loads applied in a direction approximately perpendicular to the foot.

The vehicle contact source deemed to be responsible for each type of injury is detailed in Table 4. Intrusion alone (i.e. contact with the intruding toepan only) was attributed to be the injury source for $56 \%$ of the injuries. However, it was not possible in this study to separate the effect of intrusion from crash severity. Foot interaction with pedals was deemed to be responsible for $27 \%$ of the injuries.

Figure 2 shows the relationship in this study between intrusion and injury type. From these data, pilon fractures, talus fractures and calcaneus fractures are often associated with higher residual intrusion. However, the data-set was too small to perform meaningful statistical analyses.

Table 2. Frequency of different types of ankle and hind-foot injuries

\begin{tabular}{|l|c|c|}
\hline Injury Description & $\mathbf{N}$ & $\%$ \\
\hline Ankle Malleolus & 23 & 37 \\
\hline Ankle Pilon & 13 & 21 \\
\hline Talus & 16 & 25 \\
\hline Calcaneus & 6 & 10 \\
\hline Lisfranc's & 5 & 8 \\
\hline Total & 63 & 100 \\
\hline
\end{tabular}


Table 3. Mechanisms of Injury

\begin{tabular}{|c|c|c|c|c|c|}
\hline & \multicolumn{5}{|c|}{ Injury Type } \\
\hline & $\begin{array}{c}\text { Ankle } \\
\text { Malleolus }\end{array}$ & Ankle Pilon & Talus & Calcaneus & Lisfranc's \\
\hline Mechanism & & & & & \\
\hline Avulsion & & & 3 & 1 & \\
\hline Dorsiflexion \& Inversion & & & 4 & & \\
\hline Axial Load & & & & 5 & \\
\hline Plantarflexion & & & & & 5 \\
\hline Abduction & 11 & & & & \\
\hline Adduction & 8 & & & & \\
\hline External Rotation & 4 & & & & \\
\hline Combined (axial) Loading & & 13 & & & \\
\hline Dorsiflexing Moment & & & 9 & & \\
\hline Totals & 23 & 13 & 16 & 6 & 5 \\
\hline
\end{tabular}

\begin{tabular}{|l|c|c|c|c|c|c|}
\hline & \multicolumn{6}{|c|}{ Injury Type } \\
\cline { 2 - 7 } & $\begin{array}{c}\text { Ankle } \\
\text { Malleolus }\end{array}$ & $\begin{array}{c}\text { Ankle } \\
\text { Pilon }\end{array}$ & Talus & Calcaneus & Lisfranc's & Total \\
\hline $\begin{array}{l}\text { Vehicle Contact } \\
\text { Firewall Intrusion }\end{array}$ & 10 & 9 & 11 & 4 & 1 & 35 \\
Firewall Contact & 3 & & & 1 & 1 & 2 \\
Floor Contact & & 3 & 2 & 1 & & 3 \\
$\begin{array}{l}\text { Entrapment (between facia and } \\
\text { footwell) }\end{array}$ & 2 & 1 & 2 & & & 6 \\
Pedal Contact & & & & & 3 \\
Pedal Roll-off & 23 & 13 & 16 & 6 & 5 & 63 \\
\hline Total & & & & & & \\
\hline
\end{tabular}

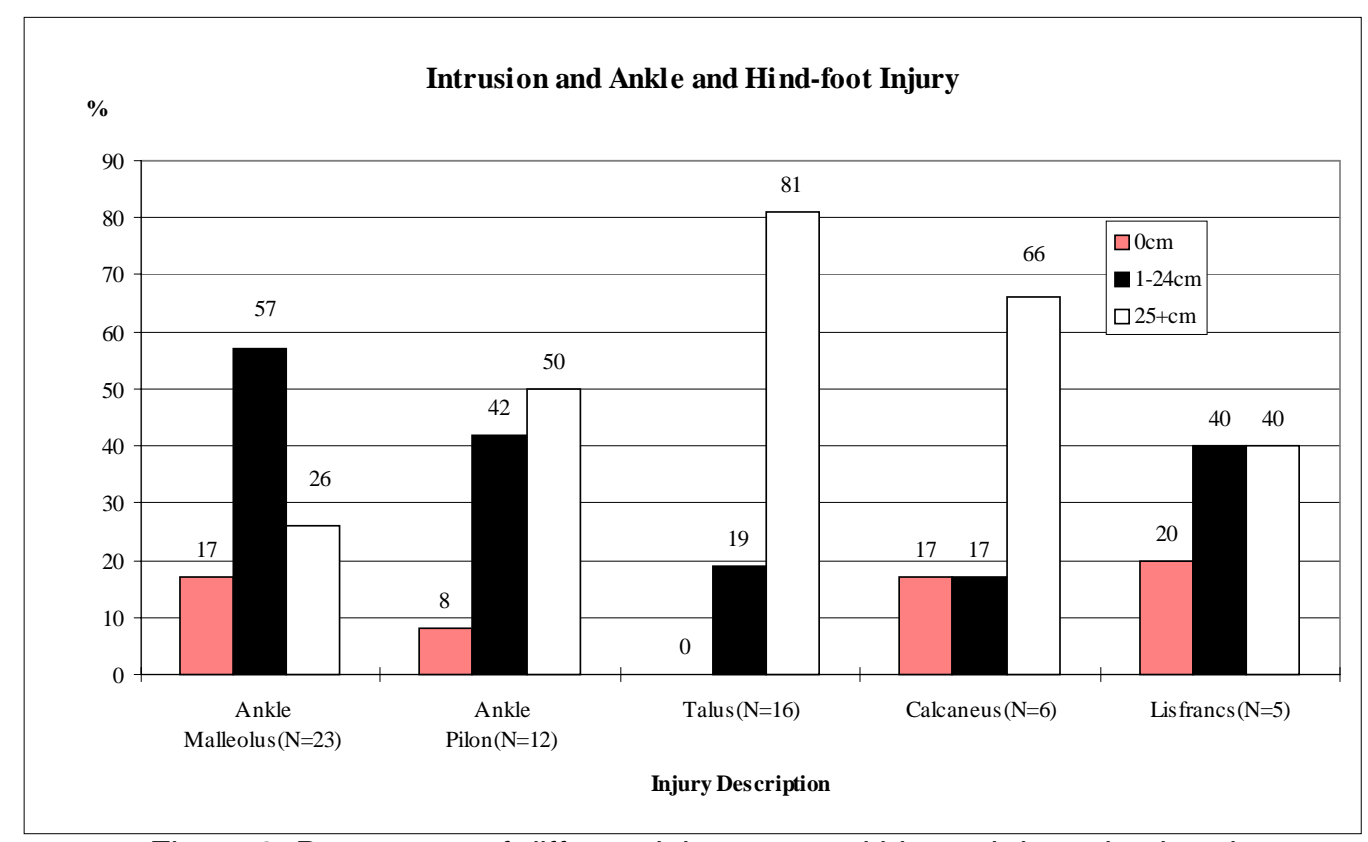

Figure 2. Percentage of different injury types within each intrusion band (data not corrected for $\Delta \mathrm{V}$ ) 
Figure 3 demonstrates the relationship between intrusion and injury impairment. An injury with an impairment score of less than 3 is unlikely to be a cause of significant long term impairment.

There would appear to be an important transition to more impairing injuries when the intrusion level exceeds 25 centimeters but the data set was too small to allow meaningful statistical analysis.

Of note is that $30 \%$ of injuries that occur in the absence of intrusion result in significant long term impairment.

Injury impairment scores (FASS-I) were also examined for all the injury types included in this study. These are shown in Table 5. When looking at injuries that have a low potential for causing long term impairment, impairment values (i.e. injuries with an impairment score of less than 3) ankle malleoli fractures figure prominently. However, when considering injuries likely to be a source of significant long term impairment (i.e. those injuries with an impairment score of three or above), ankle pilon fractures, talus fractures, calcaneus fractures and Lisfranc's fractures are most important.

A separate analysis relating the injuries' impairment scores with the vehicle contact was performed (Table 6). Intrusion of the toe-pan (firewall or wheelwell) was found to be closely associated with the highly impairing injuries. The majority of injuries related to pedal contact were of relatively low impairment potential. The role of pedals on ankle, hind-foot and mid-foot injuries is explored in the next section.

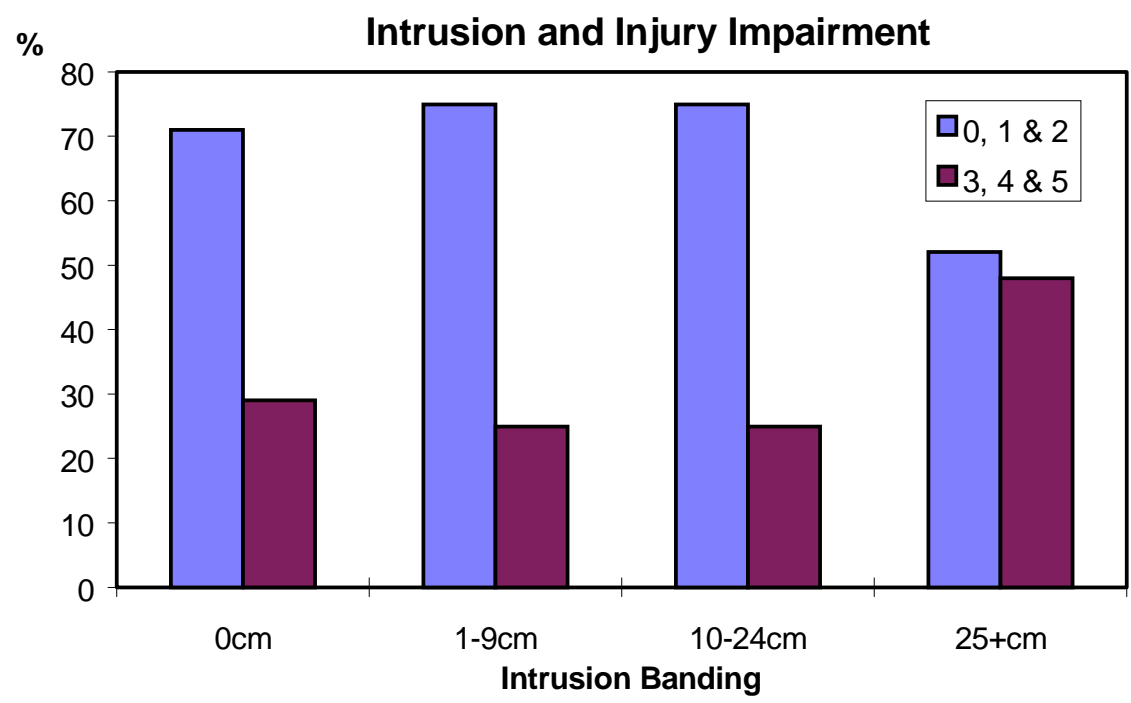

AFIS-I (Injury

Impairment) Scores

Figure 3. Percentage of low and high impairment injuries within different intrusion bands ( data not corrected for $\Delta \mathrm{V}$ ) 
Table 5. Frequency of injuries with different Injury Impairment Score for Ankle \& Hind-foot Injuries.

\begin{tabular}{|c|c|c|c|c|c|c|c|}
\hline \multirow{2}{*}{ Injury Type } & \multicolumn{6}{|c|}{ Injury Impairment Score (FASS-I) } & \\
\hline & 0 & 1 & 2 & 3 & 4 & 5 & Total \\
\hline Ankle Malleolus & 10 & 6 & 7 & - & - & - & 23 \\
\hline Ankle Pilon & - & - & 6 & - & 7 & - & 13 \\
\hline Talus & - & 8 & 2 & 5 & 1 & - & 16 \\
\hline Calcaneus & - & - & - & 5 & - & 1 & 6 \\
\hline Lisfranc's & - & - & - & 5 & - & - & 5 \\
\hline Total & 10 & 14 & 15 & 15 & 8 & 1 & 63 \\
\hline
\end{tabular}

Table 6. Frequency of Injuries with different Impairment Scores by Vehicle Contact

\begin{tabular}{|l|c|c|c|c|c|c|}
\hline & \multicolumn{6}{|c|}{ Injury Impairment Score (FASS-I) } \\
\hline & \multicolumn{2}{|c|}{ Low impairment rating } & \multicolumn{3}{c|}{ High impairment rating } \\
\hline & 0 & 1 & 2 & $\mathbf{3}$ & $\mathbf{4}$ & $\mathbf{5}$ \\
\hline Vehicle Contact & & & & & & \\
\hline Firewall/Wheel-well Intrusion & 3 & 6 & 7 & $\mathbf{7}$ & $\mathbf{7}$ & $\mathbf{1}$ \\
\hline Firewall Contact & - & - & - & $\mathbf{2}$ & - & - \\
\hline Floor & 1 & 1 & 1 & - & - & - \\
\hline Entrapment & - & - & 1 & $\mathbf{3}$ & $\mathbf{1}$ & - \\
\hline Pedal Contact & 2 & 2 & 1 & $\mathbf{3}$ & - & - \\
\hline Pedal Roll-off & 3 & 4 & 2 & - & - & - \\
\hline Total & 9 & 13 & 12 & $\mathbf{1 5}$ & $\mathbf{8}$ & $\mathbf{7}$ \\
\hline
\end{tabular}

The Effects of Pedals on Ankle and Hind-foot Injuries

Pedals were a contact source in $17 / 53$ $(32 \%)$ of injuries to the ankle and hindfoot of drivers in this study. Table 7 shows the number of different injury types attributable to pedals as a percentage of the total numbers of these injuries. $50 \%$ of malleoli fractures and $100 \%$ of Lisfranc's fractures were found to be associated with pedal contact. The pedals were not found to be important injury sources for pilon fractures, talus fractures or calcaneus fractures.
The most common injury types caused by contact with pedals are malleolus fractures (associated with the foot rolling off the pedal leading to abduction/adduction) and forefoot fractures (associated with direct loading through the foot). They are also an implied contact source for Lisfranc's fractures.

Table 7. Pedal Related Injuries as a Percentage of All Driver Injuries

\begin{tabular}{|l|c|c|c|}
\hline Injury Description & $\begin{array}{c}\text { Number of Pedal } \\
\text { Related Injuries }\end{array}$ & $\begin{array}{c}\text { Total Number of } \\
\text { Injuries to Drivers }\end{array}$ & $\%$ \\
\hline Malleolus \# & 10 & 20 & 50 \\
\hline Pilon \# & 1 & 13 & 8 \\
\hline Talus \# & 3 & 13 & 23 \\
\hline Calcaneus \# & - & 4 & - \\
\hline Lisfranc's \# & 3 & 3 & 100 \\
\hline Total & 17 & 53 & \\
\hline
\end{tabular}


Table 8. Principle Injury Mechanism for Pedal-Related Injuries

\begin{tabular}{|l|c|c|c|c|}
\hline & $\begin{array}{l}\text { Foot Pedal } \\
\text { Contact }\end{array}$ & $\begin{array}{l}\text { Foot Trapped } \\
\text { Under Pedal }\end{array}$ & $\begin{array}{l}\text { Foot Roll-off } \\
\text { Pedal }\end{array}$ & Primary Injury Mechanism \\
\hline Malleolus \# & 2 & & 8 & Abduction/Adduction \\
\hline Pilon \# & 1 & & & Axial Load \\
\hline Talus \# & 2 & & 1 & Dorsiflexing Moment \\
\hline Calcaneus \# & - & - & - & - \\
\hline Lisfranc's \# & 2 & 1 & & Plantarflexion \\
\hline Total & 7 & 1 & 9 & \\
\hline
\end{tabular}

Table 9. Frequency of Pedal Injuries with Different Impairment Scores

\begin{tabular}{|l|c|c|c|c|}
\hline \multirow{2}{*}{ Injury Mechanism } & \multicolumn{4}{|c|}{ Impairment Score (FASS-I) } \\
\cline { 2 - 5 } & $\mathbf{0}$ & $\mathbf{1}$ & $\mathbf{2}$ & $\mathbf{3}$ \\
\hline Foot Pedal Contact & 2 & 2 & 1 & 2 \\
\hline Foot Trapped Under Pedal & & - & - & 1 \\
\hline Foot Roll-off Pedal & 3 & 4 & 2 & \\
\hline
\end{tabular}

The inferred mechanisms by which pedals cause injury are of two distinct types. When the foot rolls off the pedal (usually following pre-impact braking), the foot rotates into extremes of inversion, eversion or external rotation. This mechanism is responsible for the majority of pedal related injuries (Table 8 ). Excessive rearwards movement of the pedal, usually associated with high levels of footwell intrusion, resulted in the application of high axial loads to the lower extremity and hence was responsible for the fractures of the ankle pilon and talar neck (Talus).

The majority of injuries attributed to the foot pedals were not associated with high levels of impairment (Table 9). In general, injuries generated in this manner would be unlikely to be a source of long term impairment (i.e. they had an FASS-I score of less than 3

Table 10 demonstrates the preponderance of injuries to the drivers right foot and ankle for pedal related injuries. Overall, 27 drivers sustained right leg only fractures compared to 10 drivers who sustained fractures to the left leg only $(p<0.001)$. For this subset of pedal related injuries, the right leg was found to be injured more than twice as frequently as the left leg but the numbers in this group were too small to demonstrate a statistically significant relationship. Two-thirds of these injuries were pedal roll-off injuries, suggesting that the brake pedal was responsible for the injury since this leg is used for braking in the majority, if not all cases.

Table 10. Pedal Injury Type and Leg Injured (left or right)

\begin{tabular}{|l|l|l|l|}
\hline \multirow{2}{*}{ Side Injured } & \multicolumn{3}{|c|}{ Injury Mechanism Type } \\
\cline { 2 - 4 } & $\begin{array}{l}\text { Foot } \\
\text { Pedal }\end{array}$ & $\begin{array}{l}\text { Foot Trapped } \\
\text { Under Pedal }\end{array}$ & $\begin{array}{l}\text { Foot Roll- } \\
\text { off Pedal }\end{array}$ \\
\hline Right & 4 & & 8 \\
\hline Left & 3 & 1 & 1 \\
\hline
\end{tabular}




\section{DISCUSSION}

This study identifies priorities for the prevention of AIS 2-3 lower extremity injuries in frontal impacts. It is a study based upon retrospective analysis of a representative sample of these types of injuries in the UK serious injury car crash population. A unique feature of this study is that it has used the American Foot and Ankle Orthopaedic Society's Injury Severity and Impairment Scales (FASS-I) to determine priorities for prevention of below knee injuries in frontal collisions.

By frequency alone, injuries to the ankle malleoli are the most important injury but they are neither a particularly severe nor impairing injury according to the impairment scales.

Of greater importance in terms of severity are ankle pilon fractures, calcaneus fractures and Lisfranc's joint fractures. The most important injury type in this study in terms of potential for causing significant permanent impairment is the ankle pilon fracture. However, calcaneus fractures, talus fractures and Lisfranc's joint fractures are also responsible for causing significant long term impairment.

A better understanding of the exact mechanisms of these different injuries is required and biomechanical experiments should be directed towards assessing the mechanisms and tolerances to injury of these anatomical sites in the foot and ankle.

Contact with an intruding surface was seen as the most important principal injury source for injuries in this study and was implicated in the majority of the injuries. More importantly, highly impairing injuries were found to occur when the intrusion of the toepan was severe although this does not necessarily imply a causal relationship and the relationship between collision severity, intrusion and injury 'severity' remains unclear based on analysis of this subset of CCIS data.

This study deals specifically with moderately serious injuries and so there could well be cases where severe intrusion occurs in the absence of injury. Furthermore, the data in figures $2 \& 3$ demonstrate that high severity and high impairment injuries do occur in the absence of intrusion. Intrusion may be merely a surrogate marker of collision severity (Delta-V) or it may reflect the loads applied to the foot and the risk of contact and stiffness of contacting structures. It is possible that high accelerations of short duration may occur without significant residual intrusion and so a reduction in intrusion per se may not necessarily lead to a corresponding reduction in the risk of lower extremity injury.

A limitation in this study is that the intrusion data do not allow in-depth discrimination since broad measurement banding were used. Furthermore, the residual intrusion measurement may not fully reflect the extent of dynamic intrusion that occurred during the crash and there is no information to correlate the crash pulse and intrusion (e.g. a very high load of short duration may cause no residual intrusion or a lower load of longer duration may leave significant amounts of intrusion).

It is clear from this and previous studies that toe-pan intrusion is strongly associated with serious injuries of the foot and ankle. Future studies should aim to improve the understanding of how the level, extent, site and pattern of footwell intrusion influences the risk of lower extremity injury.

Foot pedals were judged to be responsible for a large proportion of ankle and hindfoot injuries. However, the majority of injuries related to foot pedals were unlikely to lead to significant long term impairment. A small number of the more impairing injuries (pilon fractures, talus fractures and Lisfranc's fractures) were associated with pedal contact.

The mechanism of ankle malleolus fractures through pedal contact usually involved rotation of the foot about the ankle joint. Inversion, eversion and external rotation were assumed to be the principle directions of force and this is based largely on the work of Lauge-Hansen as well as clinical experience. Although dorsiflexion may be an important factor in the generation of some ankle fractures, particularly pilon fractures, there is no detailed published evidence from biomechanical studies that detail "simple" malleolar fractures being generated by dorsiflexion.

Some attention should be focused on the mitigation of pedal related injuries by:

1. preventing foot pedal roll-off

2. limiting the force applied to the foot through the pedals.

Loads applied perpendicular to the foot or parallel to the tibia (i.e. axially and possibly associated with dorsiflexion of the foot-ankle complex) were responsible for the most impairing injuries. Future dummy designs should focus on assessing the risk of injury from such axially applied loads rather than on the lesser fractures of the ankle malleolus. 
An additional consideration in a future study is occupant characteristics. Information about occupant weight and height was only available in about $60 \%$ of cases and therefore meaningful analysis regarding occupant anthropometry was not possible. Furthermore, the seated position of the occupant prior to the crash could not be determined. More detailed information would have perhaps provided an even greater understanding of the fracture mechanism than this study has allowed.

\section{CONCLUSIONS}

1. Injuries of the ankle and hindfoot constitute the most severe and disabling injuries to the lower extremities of front seat car occupants in frontal collisions.

2. Axial loads are responsible for causing the majority of impairing injuries. Injuries caused by indirectly applied forces (inversion, eversion and external rotation) are less important in terms of long term impairment.

3. Enhanced lower leg dummy design should focus on assessing the risk of injuries due to axially applied loads.

4. Toe-pan intrusion is implicated as the cause of the majority of injuries and the vast majority of highly impairing injuries.

5. Pedal associated injuries are relatively less important both in terms of their frequency and their ability to cause long term impairment. However, they do constitute a significant minority of injuries seen and there fore some attention should focus on reducing their incidence, perhaps by improving pedal design.

6. Prospective studies should address in more detail patterns of toe-pan intrusion and the effect of driver size and seating position on the risk of lower extremity injury.

\section{ACKNOWLEDGMENTS}

The work described in this paper forms part of a major biomechanics research project funded by the UK Department of the Environment, Transport and the Regions (DETR) and managed by the Transport Research Laboratory (TRL).

The accidents data for this study came from the Co-operative crash Injury Study (CCIS), which is managed by the TRL on behalf of DETR (Vehicle Standards and Engineering Division) who fund the project with Ford Motor Company Limited, Rover Group Limited, Nissan Motor Company Limited, Toyota Motor Europe and Honda R \& D Europe (UK)
Limited. The data were collected by teams from the Vehicle Safety Research Centre at Loughborough University, Birmingham Accident Research Centre and from the Vehicle Inspectorate Executive Agency.

\section{REFERENCES}

Pattimore, D et al. The Nature and Causes of Lower Limb Injuries in Car Crashes. In Proceedings of the 35th Stapp Car Crash Conference, Warrendale PA, 1991

Crandall, J R et al. Research Program to Investigate Lower Extremity Injuries. In Proceedings of the 38th Stapp Car Crash Conference, Florida, USA, 1994

Portier, L et al. Lower Leg Injuries in Real World Frontal Accidents. In Proceedings of the IRCOBI Conference, Eindhoven, Holland, 1993

Dischinger, P P; Cushing, B and Kerns, T. Lower Extremity Fractures in Motor Vehicle Collisions: Influence of Direction of Impact and Seat Belt Use. In Proceedings of the 36th AAAM Conference, Portland, Oregon, 1992.

Fildes, B et al. Lower Limb Injuries to Passenger Car Occupants. Federal Office of Road Safety, Canberra, Australia, 1994

Thomas, P; Charles, J and Fay, P. Lower Limb Injuries - The effects of Intrusion, Crash Severity and the Pedals on Injury Risk and Injury Types in Frontal Collisions. In Proceedings of the 39th Stapp Car Crash Conference, San Diego, California, USA, 1994

Otte, D; Rheinhaben, Hv and Zwipp, H. Biomechanics of Injuries to the Foot and Ankle Joint of Drivers and Improvements for an Optimal Car Floor Development. In Proceedings of the 36th Stapp Car Crash Conference, Seattle, Washington, USA, 1992

Fildes, B; Lenard, J; Lane, J C; Vulcan, P and Seyer, K. Lower Limb Injuries to Passenger Car Occupants. In Proceedings of the IRCOBI Conference, Brunnen, Switzerland 1995

Manoli, A., P. Prasad, et al. (1997). "Foot and Ankle Severity Scale." Foot and Ankle International. In Press.

Morgan, R M; Eppinger, R H and Hennessey, B C. Ankle Joint Injury Mechanisms for Adults in Frontal Automotive Impact. In Proceedings of the 35th Stapp Car Crash Conference, Warrendale PA, 1991.

Lestina, D C et al. Mechanism of Fractures in Ankle and Foot Injuries to Drivers in Motor Vehicle Crashes. 
In Proceedings of the 36th Stapp Car Crash

Conference, Seattle, Washington, USA, 1992

Levine, RS; Manoli, A; Prasad, P; Foot and Ankle

Severity Scale. In proceedings of International

Conference on Pelvic and Lower Extremity Injuries,

Washington DC, 1995.

Taylor, A M; Morris, A P; Thomas, P and Wallace, W

A. Mechanisms of Lower Extremity Injuries to Front

Seat Car Occupants - An In-Depth Accident Analysis.

Proceedings of the Hannover IRCOBI Conference,

Hannover, Germany, 1997. 


\section{APPENDIX A}

The following tables contain the definitions for the Ankle Foot Severity Scales (FASS) as developed by the Trauma Committee of the American Orthopaedic Foot and Ankle Society. The scales and definitions were developed using AIS as the basic model. The following are the definitions for Injury Severity (FASS-S) Scale.

$\begin{array}{ll}0 & \text { No injury } \\ 1 & \text { Minimal injury } \\ 2 & \text { Mild injury } \\ 3 & \text { Moderate injury } \\ 4 & \text { Severe injury } \\ 5 & \text { Very severe injury } \\ 6 & \text { Currently untreatable }\end{array}$

Similar terminology was used for the impairment scale (FASS-I), a scale that gives the unexpected permanent considering as the average permanent impairment of 100 patients treated by an average orthopaedic surgeon. If an injury had a high probability of complications, such as a displaced talar neck fracture dislocation, the complication rate was factored in when determining the average outcome for the group of one hundred patients with the listed injury.

$\begin{array}{ll}0 & \text { No impairment } \\ 1 & \text { Minimal impairment } \\ 2 & \text { Mild impairment } \\ 3 & \text { Moderate impairment } \\ 4 & \text { Severe impairment } \\ 5 & \text { Very severe impairment } \\ 6 & \text { Total impairment }\end{array}$

The following explanations were used to define each impairment level:

\section{No Impairment}

Patient has no residual signs or symptoms associated with the injury.

\section{Minimal Impairment}

Able to do all desired activities but may be slightly limited at impact sports. May have occasional discomfort requiring an OTC medication. Able to wear any type of footwear.

\section{Mild Impairment}

Unable to do impact activities, for example, unable to participate in sports such as tennis, basketball, etc. Has some limitations at work. Cannot do a job requiring constant standing, walking and climbing. Regularly uses OTC medication to control discomfort.

\section{Moderate Impairment}

Walking is limited. Can do most activities but unable to walk for long periods. Can do normal shopping but excessive walking impossible. May occasionally use cane for support. May need occasional non-opioid prescription medications for pain relief. Can do work requiring some walking but needs to be able to sit. Cannot do job requiring weight bearing. May need orthotics to control pain.

\section{Severe Impairment}

Able to walk about living quarters. Usually can weight bear but often needs to use a single walking aid (cane). Can do work requiring minimal walking and standing but needs to sit most of the time. Cannot participate in sports requiring weight bearing. Regularly uses non-opioid medications to control pain.

\section{Very Severe Impairment}

Can barely get around living quarters without walking aids. Must use walking aids or wheelchair when out house. Usually can be partially weight bearing but at times has be to non-weight bearing. Able to do sedentary work without any standing, walking or climbing. Regularly uses non-narcotic medications for pain control and may occasionally need OOP's to control pain. Only able to work in limited jobs requiring no standing, walking, or climbing.

\section{Total Impairment}

Unable to weight bear - must use walking aids or wheelchair at all times. Unable to perform any type work activities and/or household chores. Needs opioids on a regular basis. Pain very poorly controlled. 
APPENDIX B 